\title{
How to Properly Ground Your Electricity Outlets and Save
}

\author{
Handoko Suwono ${ }^{\mathrm{a}}$
}

a Datacom Informatika, Surabaya, Indonesia

\begin{abstract}
Sometime when we touch the metal parts of instruments or devices connected to wall outlet, we feel a mild electricity shock from the devices. A stingy shock that could be harmful to some people. It must be more than sixty volts that a human-body can response to it. Over than 60volt of excess electricity will damage some devices. It means the electricity is leaking. This leakage is hazardous to your health and to parts of devices such as chips in computers, USB devices or others. In some cases, it will directly damage the devices.
\end{abstract}

This leakage comes from improper grounding of the electricity wiring system.

Keywords: grounding, earth, wiring, improper, electricity, energy

\section{Introduction}

A grounding system is how we can connect the devices via an electricity outlet and nullify the excess electricity like having a surge arrester to protect the house against lightnings directly connected to earth.[2]

Grounding system is a safety measure used to help prevent people from accidentally coming in contact with electrical hazards. Think of a refrigerator. The electricity running from the outlet and through the power cord to the electrical components inside the refrigerator are electrically isolated from the metal exterior or chassis of the refrigerator.

For some reason the electricity came in contact with the chassis and the electricity would flow from the chassis of the refrigerator, through the person who touched and possibly causing injury.

By connecting a wire from the metal frame of the refrigerator to the ground, the unwanted electricity will travel through the wire and out to the earth. That wire has to be connected to something that is in turn connected to the earth or ground outside.

The process of connecting the wire to the earth is called "earthing", where in Europe the term "grounding" is used to describe the above.

\section{Identifying the problems}

Sometime when we touch the metal parts of instruments or devices connected to wall outlet, we feel a mild electricity shock from the devices. A stingy shock that could be harmful to some people. It must be more than sixty volts that a human-body can response to it. Over than 60 volt of excess electricity will damage some devices. It means the electricity is leaking. This leakage is hazardous to your health and to parts of devices such as chips in computers, USB devices or others. In some cases, it will directly damage the devices.

Where does this shock come from? Some says it came from leakage of the devices like a faulty power supply that we can replace it anyway. For most cases it will not work. The source is the improper wiring of the electricity infrastructure.

One way to overcome the problem is by making small ground facility to lessen damage caused by leakage electricity. What we do is to attach one end cable to the chassis of the appliance or other devices, screw it to the frame and nail the other end of the cable to the wall deep enough so the leak can go through the cable into the wall and to the ground. This will usually cover the minor shock problem.

Computers, televisions, microwave ovens, fluorescent lamps and many other electrical devices, may generate lots of leakage electricity that can cause damage to equipments. This situation is commonly encountered in house-holds in Indonesia.

An older wiring system, still in some parts of Indonesia, is using a two-wiring system that was built for a $110 \mathrm{v}$ ac power distribution during the Dutch east-indies era.

Without a proper grounding system. No matter how small the leakage could be, it will still be an energy loss.[3]

\section{The theory behind leakage electricity}

What happens if you have improper grounding at your house wiring system?

The electricity supply that comes from the public utility electricity power provider here in Indonesia, provides two 
wiring system of a 220volt ac environment to distribute power to the households. We need to put another wire in the households to provide the grounding system. This wire is not supplied by the power house, but we need to provide it ourselves. So there will be a use of three-wire cabling system in the internal house wiring.

\subsection{Some basic electricity}

If you remember some basic electricity for a threephase generators/transformer with an RST triangle, also known as delta-wiring system, the output will be 380volt between R-S, S-T, and T-R nodes.

In the center of the RST triangle, there is a normal point called N. The voltage between R-N, S-N, T-N is 220volt, which is the source power that will carry and distribute the electricity to our households in a two-wire version. So there will only be two wires (one pair) from the electricity distributor that comes to the households as the main source of power. The power is measured in volt-ampere rather than in watts for acquired real power in the households. In Ohm's law, the power in watts equals voltage times the current intake in electricity distribution.

So what happens, what's wrong with this? Why we need another wire for internal households wiring system?

\subsection{Source of leakage electricity}

The real problem of the electricity leakage comes from the irregular load distribution of the power house which is not balanced for the RST-N nodes. One R-N pair is heavily over-loaded and the other S-N or T-N pairs are not loaded as much during the distribution. This unbalanced load will 'shift' the $\mathrm{N}$ to an off center of the triangle and cause the leakage. That's why there will be shock because of the unbalanced load. This happen in most cases in Indonesia but not happening in Japan where you can still use a twowire outlet without proper grounding.

The calculation is like this, for 1 amp current under 220volt will result in a 220watts of power. Because of the unbalanced load, there will be more than 220va drawn from the power house. For example there will be $245 \mathrm{va}$ of electricity to get a 220 watts of real power, so there will be a lost of 25va of unreal power that you will still have to pay extra to the power provider.[4]

There are ways of measuring leakage electricity in your household wiring. System.[6]

\subsection{Problem discussion and Solution}

In internal house wiring there will be a three-wire cable that carries the electricity current. Installation of another wire in internal households wiring system. The ground-wire must be put inside the real soil for at least two meters deep, usually connected via a special submersed copper rod suitable for grounding purposes.

Most households in Indonesia are already equiped or replaced with a newer wiring system that carry $220 \mathrm{v}$ electricity distribution from the power distributor. It is conditioned and regulated that it is required to put an additional wire called the ground wire for a two-wire $220 \mathrm{v}$ ac wiring system distributed from the power house. Make sure that certain house wiring to include the ground wire in the house wiring which is a must and has been regulated.[1] The cable with additional ground wire which is a standard shielded three-wire, is widely available in Indonesia.

Use of three-prong outlets are needed with additional ground wire connected inside within household wiring instead of having or keeping the two-wiring system delivered from the power house.

Most heavy duty equipments like refrigerators, pumps, air conditioners, washing machines and many other household appliances will need these kind of outlets.[5]

Many devices as above are supplied with a proper 3-pin connector with three wires in the cable. The third cable is connected to the of the frame of the appliances and then connected to the wall three-prong outlets.

Proper grounding will not only remove this unwanted electricity, but can even make those equipments to work more efficiently.

\section{Conclusion}

While electrical grounding may have originally been considered only as a safety measure, with today's advances in electronics and technology, electrical grounding has become an essential part of everyday electricity.

Awareness of the importance of proper wiring electricity to reduce electricity consumption and provoke energy conservation to house-holds in Indonesia or elsewhere where applicable.

Putting a correct wiring system with proper grounding system at your house is mandatory to reduce un-necessary electricity consumption and therefore lessen your bill.

\section{Acknowledgements}

- EECCHI - ESDM training (2011)

http://www.konservasienergiindonesia.info/

- Creative Commons License - Attribution-

NonCommercial-ShareAlike 3.0 Unported 
Handoko Suwono / KnE Energy (2015) 77-79

\section{References}

[1] Peraturan pemerintah tentang pemakaian enersi listrik,

Persyaratan Umum Instalasi Listrik 2000 (PUIL 2000)

[2] About Electrical Grounding,

http://www.esgroundingsolutions.com/about-electrical-

grounding/what-is-electrical-grounding.php

[3] Will Electricity Leakage Create Higher Bill? 11/12/2011 4:31 AM http://cr4.globalspec.com/comment/793876/Re-Will-ElectricityLeakage-Create-Higher-Bill

[4] Homes That "Leak" Electricity, And How To Plug Them, Allan Chen, A_Chen@LBL.gov - May 20, 1997

http://www.lbl.gov/Science-Articles/Archive/leaking-watts.html
[5] Monitoring home electricity use - small appliances cause electricity leakage

http://www.canwesavetheworld.com/small-appliances-that-leakenergy.html

[6] Leakage current measurement basics

http://www.fluke.com/fluke/usen/community/fluke-news-

plus/articlecategories/electrical/leakagebasics.htm 